\title{
Article \\ Acute Effects of Muay Thai on Blood Pressure and Heart Rate in Adolescents with Overweight/Obesity
}

\author{
Bruna Thamyres Ciccotti Saraiva ${ }^{1}\left(\mathbb{D}\right.$, Wagner Luiz do Prado ${ }^{2}$, , Luiz Carlos Marques Vanderlei ${ }^{3}(\mathbb{D}$, \\ Vinícius Flávio Milanez ${ }^{4}{ }^{\mathbb{D}}$, Tatiana Machado de Mattos Damato ${ }^{3}$, Amanda Barbosa dos Santos ${ }^{1}$, \\ William Rodrigues Tebar ${ }^{5}$ and Diego Giulliano Destro Christofaro ${ }^{1, *}$
}

check for

updates

Citation: Saraiva, B.T.C.; Prado,

W.L.d.; Vanderlei, L.C.M.; Milanez,

V.F.; Damato, T.M.d.M.; Santos,

A.B.d.; Tebar, W.R.; Christofaro,

D.G.D. Acute Effects of Muay Thai on

Blood Pressure and Heart Rate in

Adolescents with Overweight/Obesity.

Obesities 2022, 2, 94-102.

https://doi.org/10.3390/

obesities 2010009

Academic Editor: Bruno Guigas

Received: 11 December 2021

Accepted: 21 February 2022

Published: 23 February 2022

Publisher's Note: MDPI stays neutral with regard to jurisdictional claims in published maps and institutional affiliations.

Copyright: (C) 2022 by the authors. Licensee MDPI, Basel, Switzerland. This article is an open access article distributed under the terms and conditions of the Creative Commons Attribution (CC BY) license (https:// creativecommons.org/licenses/by/ $4.0 /)$.

1 Department of Physical Education, Faculty of Science and Technology, Sao Paulo State University (UNESP), Presidente Prudente 19060-900, Brazil; brunatcsaraiva@gmail.com (B.T.C.S.); amanda10barbosadossantos@gmail.com (A.B.d.S.)

2 Department of Kinesiology, California State University, San Bernardino, CA 92407, USA; wagner.prado@csusb.edu

3 Department of Physiotherapy, Faculty of Science and Technology, Sao Paulo State University (UNESP), Presidente Prudente 19060-900, Brazil; lcm.vanderlei@unesp.br (L.C.M.V.) tatiana_damato@hotmail.com (T.M.d.M.D.)

4 Department of Physical Education, University of Western São Paulo (UNOESTE), Presidente Prudente 19067-175, Brazil; viniciunesp@hotmail.com

5 Center of Clinical and Epidemiological Research, University Hospital, University of São Paulo (USP), São Paulo 05508-000, Brazil; william.tebar@hotmail.com

* Correspondence: diegochristofaro@yahoo.com.br; Tel.: +55-18-3229-5723

\begin{abstract}
Background: To analyze the effects of a single session of Muay Thai (MT) on blood pressure and heart rate in adolescents with overweight/obesity. Methods: A total of 27 adolescents with overweight/obesity (12.85 \pm 2.08 years), 13 girls and 14 boys, performed $60 \mathrm{~min}$ of MT composed of general and modality-specific exercises, as well as combat at the end. Anthropometric measurements were taken and body fat (BF) was measured using DEXA. Excess weight was attested via the body mass index (BMI) and BF. Systolic blood pressure (SBP), diastolic blood pressure (DBP) and heart rate (HR) were measured by an oscillometric device before, immediately after MT, and 10, 20 and 30 min of recovery. Results: SBP decreased in boys after $20 \mathrm{~min}(\mathrm{~d}=-0.73)$ and $30 \mathrm{~min}(\mathrm{~d}=-0.78)$ of recovery, and in girls after $20 \mathrm{~min}(\mathrm{~d}=-0.56)$. DBP decreased in girls immediately after the session $(\mathrm{d}=-0.90)$ and after $10 \mathrm{~min}(\mathrm{~d}=-1.00)$; for the total sample, when analyzed across sex, DBP decreased immediately after the session $(d=-0.70)$ and after $10 \min (d=-0.52)$. No effect of MT on HR recovery was observed. Conclusions: A single MT session induces positive changes in blood pressure, with a greater impact on SBP in girls.
\end{abstract}

Keywords: martial arts; exercise; blood pressure; heart rate; obesity

\section{Introduction}

Obesity is one of the biggest public health concerns in the 21st century [1]. It is associated with many serious consequences, from foot disorders, foot and lower limb pain, to metabolic and cardiovascular problems [2-4]. In Brazil, the prevalence of children with overweight/obesity is around 30\% [5], and considering that childhood obesity problems are likely to persist and become even worst in adulthood [6], it is necessary to develop effective treatment options.

Obesity is associated with other diseases, such as endocrine and metabolic disorders [7]. This is because, in childhood and adolescence, high values of heart rate (HR), systolic blood pressure (SBP) and diastolic blood pressure (DBP) predispose a greater risk of developing cardiovascular problems in adulthood [8]. Cardiovascular diseases are the main causes of death worldwide, with systemic arterial hypertension being one of the main risk factors [9], reaching $22-44 \%$ of the Brazilian population [10]. On the other hand, recent studies have 
shown that movement quality and motor competence can improve sports commitments, improving the general health as well as the well-being of overweight and obese adults and youth [11,12], and interventions implementing quality of movement can be more efficient for the treatment of overweight and obesity than conventional exercises [12].

Studies suggest a positive effect of a single exercise bout on BP, a phenomenon called post-exercise hypotension [13]. This effect was found in several types of exercises [14,15], and also in martial arts like Tai Chi Chuan [16], Judo [17] and Karate [18], in diverse populations. However, it is worth noting that most of the above-mentioned studies concern the performance of athletes.

Furthermore, it is noteworthy that the American College of Sports Medicine [19] recommends intermittent activities for the young population, since these are similar to their daily activities, and thus, the martial arts become an alternative practice. Still, studies using the practice of martial arts are incipient in children and adolescents, especially with Muay Thai, which is characterized as an intermittent modality of moderate to high intensity [20]. However, the long-term practice of Muay Thai, i.e., 16 weeks, has already been shown to be beneficial in improving the body composition of adolescents with overweight/obesity, such as increasing lean mass and reducing body fat [21]. However, its acute effects on cardiovascular parameters are still unclear. In this sense, our hypothesis is that according to the aforementioned evidence, a Muay Thai session can contribute to a reduction in blood pressure and the resting heart rate of overweight adolescents. The aim of this study is to describe the effects of a Muay Thai session on the recovery of blood pressure and heart rate in adolescents with overweight/obesity.

\section{Materials and Methods}

\subsection{Subjects}

Adolescents were recruited through local media (television and newspapers) and social media advertisements. The inclusion criteria were: (a) not having performed physical exercises for at least six months; (b) not having any disease that would prevent the adolescent from practicing fighting activities; and (c) not taking any kind of medication.

The sample consisted of 27 adolescents (aged 10 to 17 years old) with overweight/obesity according to Cole et al. [22] and a percentage of body fat according to Williams et al. [23]. Before completing the training protocol, the participants underwent a period of adaptation/familiarization of the practice of supervised Muay Thai three times a week, for $90 \mathrm{~min}$, for two months. The study was conducted in the first half of 2016 and all returned with the Free and Informed Consent Form signed by their parents or guardians, allowing the adolescent to join the project. The project was approved by the Research Ethics Committee of the institution responsible for the study (CAAE: 26702414.0.0000.5402).

\subsection{Muay Thai Session}

The adolescents underwent $60 \mathrm{~min}$ of Muay Thai training comprised of $20 \mathrm{~min}$ of general exercise (warm-up, stretching, co-ordination, speed), $20 \mathrm{~min}$ of specific Muay Thai movements (Thai pad, gauntlets, kickers and gloves, through kicks, elbows, knees and punches) and 20 min of combat (a sparring technique performed by the instructors who only received and defended the students' blows-four 4 min rounds were performed with $30 \mathrm{~s}$ of rest). At the end of the session, Borg's subjective perception of effort scale [24], adapted by Foster [25], was presented and remained between 15-20, which is considered as high intensity. At the beginning of the session, the individuals remained seated at rest for $15 \mathrm{~min}$ and then were submitted to the session; after, the same adolescents returned to rest, seated, to complete 30 min of recovery.

\subsection{Anthropometry}

Anthropometric measurements were performed to measure body mass and height using the Fillizola digital scale (Plenna, Brazil) and Sanny's fixed stadiometer with a maximum length of two meters, respectively. All measurements were performed according 
to the methodology proposed by Freitas Jr et al. [26]. BMI was calculated using the equation: body mass in $\mathrm{kg}$ divided by height in meters squared.

\subsection{Body Fat}

To assess body fat (\%), dual energy X-ray absorptiometry equipment (DEXA) was used, with the GE Lunar-DPX-NT model equipment. All participants, wearing light clothing and barefoot (with no metal in the body), were placed on the equipment in a supine position throughout the exam, remaining immobile for an approximate time of $15 \mathrm{~min}$. The results were expressed using specific software provided with the equipment. The analysis procedures were reported in a previous study by Saraiva et al. [27]. The precision of the DEXA in terms of coefficients of variation was tested in a pilot study with 30 volunteers who were not involved in this study, and resulted in an error lower than $1 \%$.

\subsection{Sedentary Behavior}

Sedentary behavior was assessed through screen time in order to characterize the sample, in which different types of screen time behaviors were evaluated by self-report. The adolescents reported the number of hours per day during the week and on weekends that they used TVs, computers, video games, and cell phones/tablets. The sedentary behavior on weekdays and weekends was added and divided by the seven days of the week to have the sedentary behavior of hours per day. Those above $2 \mathrm{~h}$ per day were considered as sedentary [28].

\subsection{Blood Pressure and Heart Rate}

SBP, DBP and HR were measured at rest, pre-exercise and in the 1st, 10th, 20th and 30th minutes post-exercise. All measurements were performed between 6:00 p.m. and 7:30 p.m. Those evaluated were advised not to practice physical exercises $24 \mathrm{~h}$ before the training session. Measurements were performed by an automatic blood pressure monitor (Omron Healthcare, Inc., IntelliSense, model HEM 742 INT, Bannockburn, Illinois, USA) validated for BP in adolescents [29], presenting good reproducibility with intraclass correlation coefficients (ICCs) for boys (SBP from 0.71 to 0.87 and DBP from 0.46 to 0.74 ) and for girls (SBP from 0.70 to 0.87 and DBP from 0.69 to 0.86 ). The same device was also validated for HR in adolescents [30], presenting good reproducibility (ICCs from 0.82 to 0.95 for boys, and from 0.66 to 0.96 for girls). Appropriate adjustment cuffs were also used for the circumference of the evaluated arm [31]. The adopted position was seated, and on the right side with the arm at the heart line. Only one measurement was performed in each period collected and the same was used for the analyses.

\subsection{Statistical Analysis}

The Shapiro-Wilk normality test and the t-test for independent samples were used to compare the initial period between boys and girls. Descriptive analysis was performed to express the data as the mean and standard deviation. Cohen's $d$ was used to check the effect size by comparing the initial period with each recovery period within each group, in which a value of $0.20-0.49$ is considered small, $0.50-0.79$ is medium and $0.80-1.29$ is large, according to Cohen [32]. A paired t-test was also performed to compare baseline with each post-session recovery measure. A significance level of $5 \%$ ( $p$-value $\leq 0.05)$ was adopted using the Statistical Package for Social Sciences software (SPSS) for Windows (version 15.0, SPSS Inc., Chicago, IL, USA).

\section{Results}

\subsection{Sample Characterization}

A total of 27 adolescents with overweight/obesity (18 obese and 9 overweight; age $=12.85 \pm 2.08 ; \mathrm{BMI}=28.87 \pm 4.67 ; \mathrm{BF}=44.82 \pm 6.37), 14$ boys and 13 girls, participated in this study. There were no differences in age, sedentary behavior, and anthropometric variables when comparing boys and girls. Similar results were found with SBP, DBP, and 
HR at rest. However, a difference was found between body fat, in which the girls presented higher values (Table 1).

Table 1. Characterization of adolescents with overweight/obesity according to sex.

\begin{tabular}{cccc}
\hline Variables & $\begin{array}{c}\text { Boys }(\boldsymbol{n}=\mathbf{1 4}) \\
\text { Mean }(\mathrm{SD})\end{array}$ & $\begin{array}{c}\text { Girls }(\boldsymbol{n}=\mathbf{1 3}) \\
\text { Mean }(\mathrm{SD})\end{array}$ & $\boldsymbol{p}$-Value \\
\hline Age (years) & $12.93(2.16)$ & $12.77(2.08)$ & 0.847 \\
Body mass $(\mathrm{kg})$ & $76.50(19.84)$ & $72.76(15.54)$ & 0.589 \\
Height $(\mathrm{cm})$ & $161.47(10.28)$ & $157.97(7.87)$ & 0.329 \\
BMI $\left(\mathrm{kg} / \mathrm{m}^{2}\right)$ & $28.83(4.71)$ & $28.92(4.81)$ & 0.961 \\
BF $(\%)$ & $41.22(5.97)$ & $48.70(4.24)$ & $0.001^{*}$ \\
SB (h/day) & $3.33(1.18)$ & $3.85(0.88)$ & 0.211 \\
SBP (mmHg) & $122.00(10.23)$ & $117.30(12.16)$ & 0.287 \\
DBP (mmHg) & $66.14(8.39)$ & $72.53(8.25)$ & 0.057 \\
HR (bpm) & $90.85(11.88)$ & $95.84(12.72)$ & 0.302 \\
\hline
\end{tabular}

$\mathrm{SD}=$ standard deviation; $\mathrm{BMI}=$ body mass index; $\mathrm{BF}$ = body fat; $\mathrm{SBP}$ = systolic blood pressure; $\mathrm{SB}=$ sedentary behavior; $\mathrm{DBP}=$ diastolic blood pressure; $\mathrm{HR}=$ heart rate; $\mathrm{kg}=\mathrm{kilogram} ; \mathrm{cm}=$ centimeter; $\mathrm{kg} / \mathrm{m}^{2}=\mathrm{kilogram}$ per square meter; $\mathrm{mmHg}=$ millimeters of mercury; $\mathrm{bpm}=$ beats per minute; $\mathrm{h} /$ day $=$ hours per day; ${ }^{*}=p$-value $<0.05$.

\subsection{Effects of a Muay Thai Session on Systolic Blood Pressure}

When comparing the values of the Borg scale during the Muay Thai session between boys and girls, a statistical difference was observed ( $p$-value $=0.044)$, in which girls had higher values $($ boys $=16.93 \pm 1.32$; girls $=18.00 \pm 1.29$ ). The effect size was analyzed in relation to the SBP response at the beginning and 10, 20 and $30 \mathrm{~min}$ after the end of the Muay Thai training session (Table 2), and it was found that when compared to rest, immediately after the end of the session, there were significant increases in SBP $(9 \mathrm{mmHg})$ for boys, girls $(11 \mathrm{mmHg})$ and when the two groups $(10 \mathrm{mmHg})$ were considered together. After the first $10 \mathrm{~min}$ of the Muay Thai session, the SBP values decreased in relation to the baseline value, and this reduction becomes significant after $20 \mathrm{~min}$ for boys $(-6 \mathrm{mmHg})$ and girls $(-5 \mathrm{mmHg})$. After $30 \mathrm{~min}$, only boys continue to reduce SBP, while in girls it stabilizes (Table 2).

Table 2. Effect of a Muay Thai session on systolic blood pressure recovery in adolescents with overweight/obesity.

\begin{tabular}{|c|c|c|c|c|c|c|c|c|c|}
\hline & \multicolumn{9}{|c|}{ Systolic Blood Pressure (mmHg) } \\
\hline & $\begin{array}{c}\text { Mean (SD) } \\
\text { B }\end{array}$ & $\begin{array}{c}\text { Mean (SD) } \\
\text { Post }\end{array}$ & $\begin{array}{c}\mathrm{d} \\
\text { B vs. Post }\end{array}$ & $\begin{array}{c}\text { Mean (SD) } \\
10\end{array}$ & $\begin{array}{c}\text { D } \\
\text { B vs. } 10\end{array}$ & $\begin{array}{c}\text { Mean (SD) } \\
20\end{array}$ & $\begin{array}{c}\text { d } \\
\text { B vs. } 20\end{array}$ & $\begin{array}{c}\text { Mean (SD) } \\
30\end{array}$ & $\begin{array}{c}\mathrm{d} \\
\text { B vs. } 30\end{array}$ \\
\hline Boys & $122(10)$ & $131(18)$ & $0.89^{a}$ & 118 (14) & $-0.40^{\mathrm{c}}$ & $116(9)$ & $-0.73^{b}$ & $114(8)$ & $-0.78^{b, *}$ \\
\hline Girls & 117 (12) & $128(14)$ & $0.69^{b, *}$ & $115(9)$ & $-0.22^{\mathrm{c}}$ & $112(8)$ & $-0.56^{b}$ & 112 (13) & $-0.40^{\mathrm{c}}$ \\
\hline Total & $120(11)$ & $130(16)$ & $0.80^{\mathrm{a}, *}$ & $116(12)$ & $-0.26^{c}$ & $114(9)$ & $-0.44^{c, *}$ & 113 (11) & $-0.47^{c, *}$ \\
\hline
\end{tabular}

$\mathrm{B}=$ baseline; $\mathrm{vs}$. = versus; $\mathrm{mmHg}=$ millimeters of mercury; $\mathrm{SD}=$ standard deviation; $\mathrm{d}=$ effect size by Cohen's d; $10=10 \mathrm{~min} ; 20=20 \mathrm{~min} ; 30=30 \mathrm{~min}{ }^{\mathrm{a}}=$ high Cohen's d; ${ }^{b}=$ medium Cohen's d; ${ }^{c}=$ low Cohen's d; $*$ *value $<0.05$.

\subsection{Effects of a Muay Thai Session on Diastolic Blood Pressure}

There was no significant reduction in the effect size of DBP in overweight/obese adolescent boys $(-3 \mathrm{mmHg})$. In girls, however, the magnitude of DBP reduction was greater immediately after the training session $(-9 \mathrm{mmHg})$ and after the first $10 \mathrm{~min}$ $(-6 \mathrm{mmHg})$, but with 20 and $30 \mathrm{~min}$ of recovery, this magnitude decreased. The results were similar when the sample was analyzed together (both sexes) (Table 3). 
Table 3. Effect of a Muay Thai session on diastolic blood pressure recovery in adolescents with overweight/obesity.

\begin{tabular}{|c|c|c|c|c|c|c|c|c|c|}
\hline & \multicolumn{9}{|c|}{ Diastolic Blood Pressure (mmHg) } \\
\hline & $\begin{array}{c}\text { Mean (SD) } \\
\text { B }\end{array}$ & $\begin{array}{c}\text { Mean (SD) } \\
\text { Post }\end{array}$ & $\begin{array}{c}\text { d } \\
\text { B vs. Post }\end{array}$ & $\begin{array}{c}\text { Mean (SD) } \\
10\end{array}$ & $\begin{array}{c}\text { D } \\
\text { B vs. } 10\end{array}$ & $\begin{array}{c}\text { Mean (SD) } \\
20\end{array}$ & $\begin{array}{c}\text { d } \\
\text { B vs. } 20\end{array}$ & $\begin{array}{c}\text { Mean (SD) } \\
30\end{array}$ & $\begin{array}{c}\text { d } \\
\text { B vs. } 30\end{array}$ \\
\hline Boys & $66(8)$ & $66(9)$ & -0.18 & $66(8)$ & 0.00 & $67(10)$ & -0.18 & $63(8)$ & $-0.42^{\mathrm{c}}$ \\
\hline Girls & $73(8)$ & $64(10)$ & $-0.90^{a, *}$ & $66(6)$ & $-1.00^{a, *}$ & $70(8)$ & $-0.47^{\mathrm{c}}$ & $71(13)$ & $-0.34^{\mathrm{c}}$ \\
\hline Total & $69(9)$ & $65(9)$ & $-0.70^{b, *}$ & $66(7)$ & $-0.52^{b}$ & $69(9)$ & 0.03 & $67(11)$ & $-0.20^{\mathrm{c}}$ \\
\hline
\end{tabular}

$\mathrm{B}=$ baseline $; \mathrm{mmHg}=$ millimeters of mercury; $\mathrm{SD}=$ standard deviation; $\mathrm{d}=$ effect size by Cohen's d; $10=10 \mathrm{~min}$ $20=20 \mathrm{~min} ; 30=30 \mathrm{~min}^{\mathrm{a}}{ }^{=}$high Cohen's d; ${ }^{\mathrm{b}}=$ medium Cohen's d; ${ }^{\mathrm{c}}=$ low Cohen's d; ${ }^{*}=p$-value $<0.05$.

\subsection{Effects of a Muay Thai Session on Heart Rate}

There was a significant increase in the size of the resting heart rate effect right after the end of the session, both in the sample stratified by sex (boys, $40 \mathrm{bpm}$; and girls, $32 \mathrm{bpm}$ ) and in the joint analysis of the sexes $(37 \mathrm{bpm})$ (Table 4$)$. Despite the reduction in heart rate at rest compared to the post-session period, the values were not equal to or lower than the initial period $10 \mathrm{~min}$ (boys, $24 \mathrm{bpm}$; girls, $18 \mathrm{bpm}$; and both, $-21 \mathrm{bpm}$ ), $20 \mathrm{~min}$ (boys, $29 \mathrm{bpm}$; girls, $23 \mathrm{bpm}$; and both, $-26 \mathrm{bpm}$ ) and $30 \mathrm{~min}$ after the end of the training session (boys, $31 \mathrm{bpm}$; girls, $25 \mathrm{bpm}$; and both, $-28 \mathrm{bpm}$ ). Heart rates remained high in the sample $30 \mathrm{~min}$ after the end of the training session, without recovery from baseline levels (Figure 1).

Table 4. Effect of a Muay Thai session on heart rate recovery in adolescents with overweight/obesity.

\begin{tabular}{|c|c|c|c|c|c|c|c|c|c|}
\hline & \multicolumn{9}{|c|}{ Heart Rate (bpm) } \\
\hline & $\begin{array}{c}\text { Mean (SD) } \\
\text { B }\end{array}$ & $\begin{array}{c}\text { Mean (SD) } \\
\text { Post }\end{array}$ & $\begin{array}{c}\text { d } \\
\text { B vs. Post }\end{array}$ & $\begin{array}{c}\text { Mean (SD) } \\
10\end{array}$ & $\begin{array}{c}\text { D } \\
\text { B vs. } 10\end{array}$ & $\begin{array}{c}\text { Mean (SD) } \\
20\end{array}$ & $\begin{array}{c}\text { d } \\
\text { B vs. } 20\end{array}$ & $\begin{array}{c}\text { Mean (SD) } \\
30\end{array}$ & $\begin{array}{c}\text { d } \\
\text { B vs. } 30\end{array}$ \\
\hline Boys & 91 (12) & 131 (18) & $2.67^{\mathrm{a}, *}$ & 107 (11) & $0.96^{\mathrm{a}, *}$ & $102(11)$ & $0.64^{b, *}$ & $100(10)$ & $0.59^{b, *}$ \\
\hline Girls & $96(13)$ & $128(14)$ & $2.04^{\mathrm{a}, *}$ & 110 (10) & $1.20^{\mathrm{a}, *}$ & 105 (13) & $0.78^{b, *}$ & 103 (11) & $0.52^{b, *}$ \\
\hline Total & $93(12)$ & $130(16)$ & $2.03^{a, *}$ & 109 (11) & $1.03^{a, *}$ & 104 (12) & $0.64^{b, *}$ & $102(10)$ & $0.59^{b, *}$ \\
\hline
\end{tabular}

$\mathrm{B}=$ baseline; $\mathrm{bpm}=$ beats per minute; $\mathrm{SD}=$ standard deviation; $\mathrm{d}=$ effect size by Cohen's $\mathrm{d} ; 10=10 \mathrm{~min}$; $20=20 \mathrm{~min} ; 30=30 \mathrm{~min}^{\mathrm{a}}=$ high Cohen's d; $^{\mathrm{b}}=$ medium Cohen's d; ${ }^{\mathrm{c}}=$ low Cohen's d; ${ }^{*}=p$-value $<0.05$.
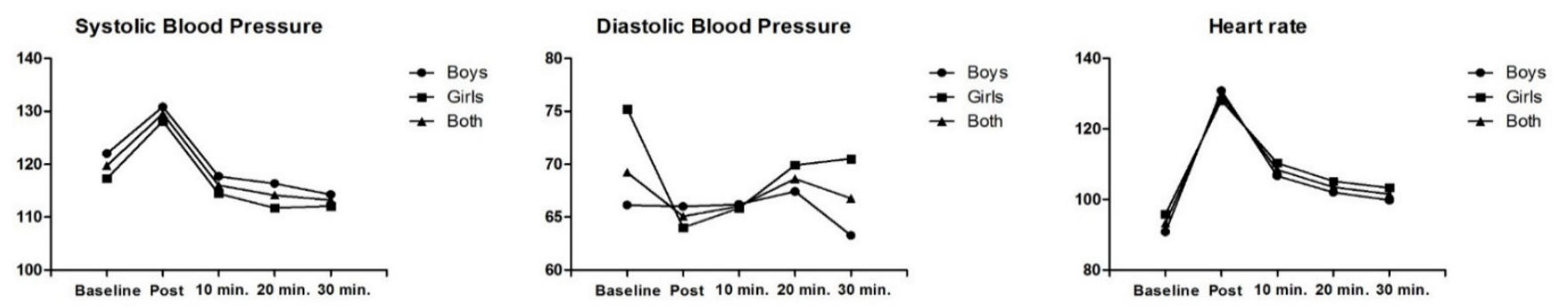

Figure 1. Cardiovascular parameters in adolescents with overweight/obesity after a Muay Thai training session.

\section{Discussion}

The present study investigated the effects of a single Muay Thai training session on the recovery of blood pressure and heart rate in overweight/obese adolescents according to sex. The results of this study indicate that a single session of Muay Thai was able to cause hypotension in SBP after $20 \mathrm{~min}$ of exercise in boys and girls, and post $30 \mathrm{~min}$ in boys only, and in DBP in girls and both sexes shortly after exercise and after $10 \mathrm{~min}$. For HR, however, there was no recovery from initial values, regardless of sex in overweight/obese adolescents. 


\subsection{Systolic and Diastolic Blood Pressure}

A possible explanation for the fact that only male SBP continued to decrease after $30 \mathrm{~min}$ is that females would have less support for autonomic tone to regulate blood pressure, as well as a lesser effectiveness of the components that regulate the baroreflex [33]. On the other hand, there was a reduction in SBP after $20 \mathrm{~min}$ for both sexes, and the present study corroborates in parts with Dantas et al. [16] who, despite using different samples, observed a reduction in SBP in patients with peripheral arterial disease after a 40 min session of Tai Chi Chuan, compared to a control group session. However, there was an increase in DBP after 50 min of exercise and there was no change in HR in the study by Dantas et al. [16]. The difference between the increase in DBP in the study by Dantas et al. [16] and the present study may have happened due to differences in the specificities of the sample between the studies.

Sales et al. [18] analyzed the effect of hypotension after a 50 min session of contact karate in young male athletes compared to a control session, in which individuals remained seated at all times. Blood pressure before and after sessions every $15 \mathrm{~min}$ until $60 \mathrm{~min}$ of recovery was analyzed, and it was observed that the contact karate session was effective in reducing BP in young normotensive individuals, and that the reduction can last for at least $60 \mathrm{~min}$ after exercise. Possible mechanisms responsible for post-exercise hypotension are decreased sympathetic activity, baroreflex sensitivity, the release of nitric oxide by the endothelium and also by reducing cardiac output [34]. It is recognized in the literature that the reductions in this period are $3.2 \mathrm{mmHg}$ in SBP and $1.8 \mathrm{mmHg}$ in DBP [35], but the reduction is greater during the first hours after exercise. Thus, the reduction in SBP obtained by Muay Thai $(8 \mathrm{mmHg})$ in boys can be considered clinically relevant for this audience, since the literature indicates that reductions above $5 \mathrm{mmHg}$ reduce the risk of death from cardiovascular diseases by $9 \%$ [36].

Considering martial arts, but with different characteristics from Muay Thai, Simao et al. [17] evaluated blood pressure in unmedicated hypertensive judo athletes after 60 min of Judo training, every $10 \mathrm{~min}$ until $60 \mathrm{~min}$ of recovery after exercise, and did not observe significant differences when compared to resting values. The Judo modality has an anaerobic predominance, which may explain the findings of Simao et al. [17], since aerobic exercises are the most recommended to promote hypotension in normotensive individuals or with hypertension [37], while Muay Thai is a predominantly aerobic modality, thus being able to explain the post-exercise hypotension effect on SBP. Furthermore, weight status impacts the mechanisms of post-exercise hypotension [38]. Overweight individuals are observed to have greater reductions in cardiac output and post-exercise systolic volume, as well as smaller reductions in total peripheral resistance, when compared with eutrophic individuals [39].

Significant reductions in DBP were observed right after the session and after $10 \mathrm{~min}$ of recovery in the girls' group and in the group with both sexes. One hypothesis is that the girls presented higher values of body fat, and consequently required greater effort and reported greater intensity. Despite this, studies like Springer et al. [40] and O'Connor et al. [41] show that females tend to overestimate intensity using the Borg scale. It is worth mentioning that the protocol and the exercises administered were the same for both sexes.

\subsection{Heart Rate}

Some types of treatment have been used for the cardiovascular health of obese subjects, such interferential current application [42], for example. In this sense, physical activity can also be another type of treatment for cardiovascular health in obese people, including pediatric populations. For HR, studies with other exercise modalities found an increase in HR during the recovery period [43], due to the increase in sympathetic modulation to the heart [44], which in addition to increasing HR, also increases stroke volume and cardiac output [45]. These findings were similar to those observed in the present study, in which after $30 \mathrm{~min}$ of recovery from the Muay Thai session, HR values did not return to the resting state. However, Nikolaidis et al. [46] observed that after a intervention consisting of five 
weekly sessions during a preparatory competition period (each session lasting 60-90 min) in adolescent Taekwondo athletes of both sexes, there was a decrease in HR values (14 bpm). This discrepancy in the results can be justified not only by the individuals in the present study being overweight, since the literature indicates that obesity reduces the activity of the autonomic system [47], but also because they are insufficiently physically preventing the return of HR values to resting levels. In addition, the Taekwondo practitioners were athletes, eutrophic and had higher levels of physical fitness.

Buchheit et al. [48] observed that the recovery from parasympathetic activity occurs 1 to $48 \mathrm{~h}$ post-exercise and this can vary according to the changes induced by exercise. Thus, another explanation for the non-recovery of HR, as well as the absence of greater hypotensive effects of BP, may be due to the intensity of the training session, in which it presented high intensity. This is considering that studies show that even in trained individuals, the greater the intensity, the recovery of HR is significantly slower [49]. On the other hand, overweight adolescents tend to have sympathetic vagal dysfunction of the heart that impairs CF baroreflex control mechanisms [50].

Weight status is important within recovery mechanisms, since overweight/obesity is associated with decreased HR recovery, delayed vagal reactivation, and impaired postexercise hypotension in young females [38]. Moreover, the literature shows that conditions such as specifically abdominal obesity, just like BMI, reduce the recovery of HR [38,50]. In addition, the recovery time (30 $\mathrm{min}$ ) may not have been enough, and perhaps with a longer recovery time it would cause a difference.

\subsection{Limitations}

Among the limitations of this study, we can consider the short recovery time, since other studies have observed better results with longer recovery times $[16,18]$. Failure to assess metabolic factors such as blood glucose, cholesterol and diabetes should also be considered, since they may have influenced this relationship. Moreover, the adaptation and familiarization time and the lack of a control group may have had an effect. Strengths of the study include the type of sport used, Muay Thai, and the specificity of the sample, composed of overweight adolescents, a population that is more likely to develop cardiovascular problems.

\section{Conclusions}

In conclusion, a single session of Muay Thai was able to reduce the SBP of boys and girls, and the DBP of girls, and when analyzed, across both sexes in the same group. For HR, the 30 min recovery was not enough to recover the values of the initial period, and these findings were similar for boys, girls, and when analyzing both sexes in the same group.

Author Contributions: Conceptualization, B.T.C.S., W.L.d.P., V.F.M., W.R.T., L.C.M.V., A.B.d.S. and T.M.d.M.D.; methodology, B.T.C.S.; formal analysis, W.R.T. and V.F.M.; investigation, A.B.d.S. and T.M.d.M.D.; data curation, A.B.d.S. and T.M.d.M.D.; writing-original draft preparation, B.T.C.S. and D.G.D.C.; writing一review and editing, B.T.C.S., W.L.d.P., V.F.M., W.R.T., L.C.M.V. and T.M.d.M.D.; supervision, D.G.D.C.; project administration, B.T.C.S., A.B.d.S. and D.G.D.C.; funding acquisition, D.G.D.C. and L.C.M.V. All authors have read and agreed to the published version of the manuscript.

Funding: This research was funded in part by Coordenação de Aperfeiçoamento de Pessoal de Nível Superior-Brasil (CAPES)_Finance Code 001.

Institutional Review Board Statement: The study was conducted according to the guidelines of the Declaration of Helsinki and approved by the Ethics Committee of Sao Paulo State University (UNESP) (26702414.0.0000.5402 March 2014).

Informed Consent Statement: Informed consent was obtained from all subjects involved in the study.

Data Availability Statement: Data are available upon request from diegochristofaro@yahoo.com.br.

Acknowledgments: We acknowledge the adolescents and parents or guardians who participated in the study, as well as professional partners who assisted in the training sessions and collections. 
Conflicts of Interest: The authors declare no conflict of interest.

\section{References}

1. Güngör, N.K. Overweight and obesity in children and adolescents. J. Clin. Res. Pediatr. Endocrinol. 2014, 6, 129-143. [CrossRef] [PubMed]

2. Kim, A.; Shah, A.S.; Nakamura, T. Extracellular vesicles: A potential novel regulator of obesity and its associated complications. Children 2018, 5, 152. [CrossRef] [PubMed]

3. Umer, A.; Kelley, G.A.; Cottrell, L.E.; Giacobbi, P., Jr.; Innes, K.E.; Lilly, C.L. Childhood obesity and adult cardiovascular disease risk factors: A systematic review with meta-analysis. BMC Public Health 2017, 17, 683. [CrossRef]

4. Jiménez-Cebrián, A.M.; Roman-Bravo, P.D.; Morente-Bernal, M.F.; Alonso-Ríos, J.A.; De-la-Cruz-Torres, B.; Romero-Morales, C.; Navarro-Flores, E.; Montiel-Luque, A. Influence of childhood overweight and obesity on foot and lower limb pain in a population of primary school children. Arch. Med. Sci. 2020. [CrossRef]

5. Flores, L.S.; Gaya, A.R.; Petersen, R.D.; Gaya, A. Trends of underweight, overweight, and obesity in Brazilian children and adolescents. J. Pediatr. 2013, 89, 456-461. [CrossRef] [PubMed]

6. Singh, A.S.; Mulder, C.; Twisk, J.W.; Van Mechelen, W.; Chinapaw, M.J. Tracking of childhood overweight into adulthood: A systematic review of the literature. Obes. Rev. 2008, 9, 474-488. [CrossRef]

7. Christofaro, D.G.; Fernandes, R.A.; Oliveira, A.R.; Freitas Júnior, I.F.; Barros, M.V.; Ritti-Dias, R.M. The association between cardiovascular risk factors and high blood pressure in adolescents: A school-based study. Am. J. Hum. Biol. 2014, 26, 518-522. [CrossRef]

8. Juonala, M.; Magnussen, C.G.; Berenson, G.S.; Alison, V.; Trudy, L.B.; Matthew, A.S.; Srinivasan, S.R.; Daniels, S.R.; Davis, P.H.; Cong Sun, W.C.; et al. Childhood adiposity, adult adiposity, and cardiovascular risk factors. N. Engl. J. Med. 2011, 365, 1876-1885. [CrossRef] [PubMed]

9. Mendis, S.; Davis, S.; Norrving, B. Organizational update: The world health organization global status report on noncommunicable diseases 2014; one more landmark step in the combat against stroke and vascular disease. Stroke 2015, 46, 121-122. [CrossRef]

10. Diretrizes, V. Brasileiras de Hipertensão Arterial. Arq. Bras. Cardiol. 2007, 89, e24.

11. Trecroci, A.; Invernizzi, P.L.; Monacis, D.; Colella, D. Actual and perceived motor competence in relation to body mass index in primary school-aged children: A systematic review. Sustainability 2021, 13, 9994. [CrossRef]

12. Cavaggioni, L.; Gilardini, L.; Redaelli, G.; Croci, M.; Capodaglio, P.; Gobbi, M.; Bertoli, S. Effects of a randomized home-based quality of movement protocol on function, posture and strength in outpatients with obesity. Healthcare 2021, 9, 1451. [CrossRef] [PubMed]

13. Kenney, M.J.; Seals, D.R. Postexercise hypotension: Key features, mechanisms, and clinical significance. Hypertension 1993, $22,653-664$. [CrossRef] [PubMed]

14. Cornelissen, V.A.; Verheyden, B.; Aubert, A.E.; Fagard, R.H. Effects of aerobic training intensity on resting, exercise and post-exercise blood pressure, heart rate and heart-rate variability. J. Hum. Hypertens. 2010, 24, 175-182. [CrossRef]

15. Araújo, J.P.; Silva, E.D.; Silva, J.C.G.; Souza, T.S.P.; Lima, E.O.; Guerra, I.; Sousa, M.S.C. The acute effect of resistance exercise with blood flow restriction with hemodynamic variables on hypertensive subjects. J. Hum. Kinet. 2014, 43, 79-85. [CrossRef] [PubMed]

16. Dantas, F.F.O.; Santana, F.S.; Silva, T.S.R.; Cucato, G.G.; Farah, B.Q.; Ritti-Dias, R.M. Acute effects of t'ai chi chuan exercise on blood pressure and heart rate in peripheral artery disease patients. J. Altern. Complement. Med. 2016, 22, 375-379. [CrossRef]

17. Simao, R.; Deus, J.; Miranda, F.; Lemos, A.; Baptista, L.A. Hypotensive effects in hypertenses after judo class. Fit. Perf. J. 2007, 6, 116-120. [CrossRef]

18. Sales, M.M.; Sousa, C.V.; Sampaio, W.B.; Ernesto, C.; Browne, R.A.; Moraes, J.F.V.N.; Motta-Santos, D.; Moraes, M.R.; Lewis, J.E.; Simões, G.S.; et al. Contact karate promotes post-exercise hypotension in young adult males. Asian J. Sports Med. 2016, 7, e33850.

19. American College of Sports Medicine. Physical activity and bone health. Med. Sci. Sports Exerc. 2004, 36, 1985-1996. [CrossRef]

20. Crisafulli, A.; Vitelli, S.; Cappai, I.; Milia, R.; Tocco, F.; Melis, F.; Concu, A. Physiological responses and energy cost during a simulation of a muay thai boxing match. Appl. Physiol. Nutr. Metab. 2009, 34, 143-150. [CrossRef]

21. Saraiva, B.T.C.; Vanderlei, L.C.M.; Scarabottolo, C.C.; Christofaro, D.G.D.; Silva, G.C.R.; Freitas Júnior, I.F.; Vanderlei, L.C.M.; Ritti-Dias, R.M.; Milanez, V.F. Effects of 16 weeks of muay Thai training on the body composition of overweight/obese adolescents. J. Martial Arts Anthrop. 2021, 21, 35-44.

22. Cole, T.J.; Bellizzi, M.C.; Flegal, K.M.; Dietz, W.H. Establishing a standard definition for child overweight and obesity worldwide: International survey. Br. Med. J. 2000, 320, 1240-1243. [CrossRef] [PubMed]

23. Williams, D.P.; Going, S.B.; Lohman, T.G.; Harsha, D.W.; Srinivasan, S.R.; Webber, L.S.; Berenson, G.S. Body fatness and risk for elevated blood pressure, total cholesterol, and serum lipoprotein rations in children and adolescents. Am. J. Public. Health 1992, 8 , 358-363. [CrossRef] [PubMed]

24. Borg, G.; Hassmén, P.; Lagerström, M. Perceived exertion related to heart rate and blood lactate during arm and leg exercise. Eur. J. Appl. Physiol. Occup. Physiol. 1987, 56, 679-685. [CrossRef]

25. Foster, C. Monitoring training in athletes with reference to overtraining syndrome. Med. Sci. Sports Exerc. 1998, 30, 1164-1168. [CrossRef]

26. Freitas, I.F., Jr. Padronização de Técnicas Antropométricas; Cultura Acadêmica: Sao Paulo, Brazil, 2009. 
27. Saraiva, B.T.C.; Agostinete, R.R.; Júnior, I.F.F.; de Sousa, D.E.R.; Gobbo, L.A.; Tebar, W.R.; Christofaro, D.G.D. Association between handgrip strength and bone mineral density of Brazilian children and adolescents stratified by sex: A cross-sectional study. BMC Pediatr. 2021, 21, 207. [CrossRef]

28. Christofaro, D.G.; Fernandes, R.A.; Gerage, A.M.; Alves, M.J.; Polito, M.D.; Oliveira, A.R. Validation of the omron HEM 742 blood pressure monitoring device in adolescents. Arq. Bras. Cardiol. 2009, 92, 10-15. [CrossRef]

29. Zanuto, E.F.; Saraiva, B.T.C.; Vanderlei, L.C.M.; Costa Júnior, P.; Agostinete, R.R.; Zanuto, E.A.; Fernandes, R.A.; Christofaro, D.G.D. Comparison of resting heart rate measured using a cardiac monitor and an oscilometric device in adolescents: Analysis of sensitivity and specificity. Medicina 2016, 49, 277-283.

30. Araújo, T.L.; Lopes, M.V.O.; Guedes, N.G.; Cavalcantes, T.F.; Moreira, R.P.; Chaves, E.S. Dimensões de manguitos para crianças e adolescentes: Estudo em uma cidade no nordeste do Brasil. Rev. Lat. Am. Enferm. 2008, 16, 877-882.

31. Cohen, J. Statistical Power Analysis for the Behavioral Sciences, 2nd ed.; Lawrence Erlbaum Associates: Hillsdale, NY, USA, 1988.

32. Christou, D.D.; Jones, P.P.; Jordan, J.; Diedrich, A.; Robertson, D.; Seals, D.R. Women have lower tonic autonomic support of arterial blood pressure and less effective baroreflex buffering than men. Circulation 2005, 111, 494-498. [CrossRef]

33. Halliwill, J.R.; Buck, T.M.; Lacewell, A.N.; Romero, S.A. Postexercise hypotension and sustained postexercise vasodilatation: What happens after we exercise? Exp. Physiol. 2013, 98, 7-18. [CrossRef] [PubMed]

34. Pescatello, L.S.; Kulikowich, J.M. The after effects of dynamic exercise on ambulatory blood pressure. Med. Sci. Sports Exerc. 2001, 33, 1855-1861. [CrossRef] [PubMed]

35. Stamler, R. Implications of the INTERSALT study. Hypertension 1991, 17, 16-20. [CrossRef] [PubMed]

36. MacDonald, J.R. Potential causes, mechanisms, and implications of post exercise hypotension. J. Hum. Hypertens. 2002, 16, 225-236. [CrossRef]

37. El Agaty, S.M.; Kirmani, A.; Labban, E. Heart rate variability analysis during immediate recovery from exercise in overweight/obese healthy young adult females. Ann. Noninvasive Electrocardiol. 2017, 22, e12427. [CrossRef]

38. Hamer, M.; Boutcher, S.H. Impact of moderate overweight and body composition on postexercise hemodynamic responses in healthy men. J. Hum. Hypertens. 2006, 20, 612-617. [CrossRef]

39. Springer, B.K.; Pincivero, D.M. Differences in ratings of perceived exertion between the sexes during single-joint and whole-body exercise. J. Sports Sci. 2010, 28, 75-82. [CrossRef]

40. O'Connor, P.J.; Poudevigne, M.S.; Pasley, J.D. Perceived exertion responses to novel elbow flexor eccentric action in women and men. Med. Sci. Sports Exerc. 2002, 34, 862-868. [CrossRef]

41. De-la-Cruz-Torres, B.; Martínez-Jiménez, E.; Navarro-Flores, E.; Palomo-López, P.; Abuín-Porras, V.; Díaz-Meco-Conde, R.; López-López, D.; Romero-Morales, C. Heart rate variability monitoring during interferential current application in the lower back area: A cross-sectional study. Int J. Environ. Res. Public Health 2021, 18, 3394. [CrossRef]

42. Rezk, C.C.; Marrache, R.C.; Tinucci, T.; Mion, D., Jr.; Forjaz, C.L. Post-resistance exercise hypotension, hemodynamics, and heart rate variability: Influence of exercise intensity. Euro. J. Appl. Physiol. 2006, 98, 105-112. [CrossRef]

43. Scott, J.M.; Esch, B.T.; Lusina, S.J.; McKenzie, D.C.; Koehle, M.S.; Sheel, A.W.; Warburton, D.E. Post-exercise hypotension and cardiovascular responses to moderate orthostatic stress in endurance-trained males. Appl. Physiol. Nutr. Metabol. 2008, 33, 246-253. [CrossRef] [PubMed]

44. Brum, P.C.; Forjaz, C.L.M.; Tinucci, T.; Negrão, C.E. Adaptações agudas e crônicas do exercício físico no sistema cardiovascular. Rev. Paul. Educ. Fis. 2004, 18, 21-31.

45. Nikolaidis, P.T.; Chtourou, H.; Torres-Luque, G.; Tasiopoulos, I.G.; Heller, J.; Padulo, J. Effect of a six-week preparation period on acute physiological responses to a simulated combat in young national-level taekwondo athletes. J. Hum. Kinet. 2015, 47, 115-125. [CrossRef] [PubMed]

46. Nagai, N.; Moritani, T. Effect of physical activity on autonomic nervous system function in lean and obese children. Int. J. Obes. 2004, 28, 27-33. [CrossRef]

47. Buchheit, M.; Laursen, P.B.; Al Haddad, H.; Ahmaidi, S. Exercise-induced plasma volume expansion and post-exercise parasympathetic reactivation. Eur. J. Appl. Physiol. 2009, 105, 471-481. [CrossRef]

48. Mann, T.N.; Webster, C.; Lamberts, R.P.; Lambert, M.I. Effect of exercise intensity on post-exercise oxygen consumption and heart rate recovery. Eur. J. Appl. Physiol. 2014, 114, 1809-1820. [CrossRef]

49. Rabbia, F.; Silke, B.; Conterno, A. Assessment of cardiac autonomic modulation during adolescent obesity. Obes. Res. 2003, 11, 541-548 [CrossRef]

50. Lind, L.; Andren, B. Heart rate recovery after exercise is related to the insulin resistance syndrome and heart rate variability in elderly men. Am. Heart J. 2002, 144, 666-672. [CrossRef] 